\title{
Post-retrieval effects of icv infusions of hemicholinium in mice are dependent on the age of the original memory
}

\author{
Mariano M. Boccia, ${ }^{1,3}$ Mariano G. Blake, ${ }^{1}$ Gabriela B. Acosta, ${ }^{2}$ and Carlos M. Baratti ${ }^{1}$ \\ ${ }^{1}$ Laboratorio de Neurofarmacología de los Procesos de Memoria, Cátedra de Farmacología, Facultad de Farmacia y Bioquímica, \\ Universidad de Buenos Aires, C1113AAD, Capital Federal, Argentina; ${ }^{2}$ Instituto de Investigaciones Farmacológicas (ININFA), \\ Consejo Nacional de Investigaciones Cientificas y Técnicas (CONICET), Capital Federal, C1113AAD, Argentina
}

\begin{abstract}
CF-1 male mice were trained in an inhibitory avoidance task using a high footshock $(1,2 \mathrm{~mA}, 50 \mathrm{~Hz}, 1 \mathrm{sec})$ in order to reduce the influence of extinction on retention performance. At 2, 7, 14, or $30 \mathrm{~d}$ after training, the first retention test was performed and hemicholinium (HC-3, $1.0 \mu \mathrm{g} /$ mice), a specific inhibitor of high-affinity choline uptake in brain cholinergic neurons, was given intracerebroventricularly immediately after. Twenty four hours after treatment, mice were tested in an inhibitory avoidance task during five consecutive days, each $24 \mathrm{~h}$ apart. Retention performance was impaired by HC-3 when the first re-exposure took place at 2, 7, or $14 \mathrm{~d}$, but the effect was no longer seen when re-exposure occurred $30 \mathrm{~d}$ after training. We did not find spontaneous recovery $21 \mathrm{~d}$ after training, when memory was retrieved $2 \mathrm{~d}$ after training and HC-3 was given immediately after. Although we cannot definitively discard a retrieval deficit, this lack of spontaneous recovery is in accordance with the storage-deficit interpretation. These results confirm and extend previous ones, suggesting that central cholinergic mechanisms are involved in the hypothetical reconsolidation memory processes of an inhibitory avoidance task in mice and also suggest that this participation depends on the "age" of the original memory trace. This implies that the vulnerability of a reactivated memory to a specific treatment, as the one used in this study, inversely correlates with the age of the original memory, and it is likely to determine memory reconsolidation processes.
\end{abstract}

Long-term memory of new learning information is achieved through a process known as memory consolidation (McGaugh 1966, 2000), which requires protein synthesis (Davis and Squire 1984). It is accepted that once consolidation is completed, memory becomes permanent (Squire and Alvarez 1995). However, it has also been suggested that reactivation (retrieval) of the original memory again makes it sensitive to disruption, since several post-retrieval treatments impair or enhance it (Misanin et al. 1968; DeVietti et al. 1977; Horne et al. 1997; Rodriguez et al. 1999; Sara 2000; Nader 2003). This new period of sensitivity coined the term reconsolidation, suggesting the "reconsolidation" hypothesis. Reconsolidation theorists, in most cases, describe post-retrieval manipulations in terms of their deleterious effects on the original memory (Dudai and Eisenberg 2004; Alberini 2005); they are at least controversial and surrounded by apparently conflicting data (Dudai and Eisenberg 2004). In this sense, one point that deserves attention is that in several studies the post-reactivation amnesic effects appear to be dependent on the age of the reactivated memory (Milekic and Alberini 2002; for review, see Dudai and Eisenberg 2004). Thus, young reactivated memories were more susceptible to disruption than older ones (Litvin and Anokhin 2000; Milekic and Alberini 2002; Eisenberg and Dudai 2004). Previous results (Boccia et al. 2004) demonstrated that the immediate post-training icv administration of hemicholinium (HC-3) (1 $\mu \mathrm{g})$, a specific inhibitor of the highaffinity choline uptake (HACU) in brain cholinergic neurons, impaired retention test performance of a one-trial step-through inhibitory avoidance response in adult male CF-1 mice. The effect was observed not only $48 \mathrm{~h}$ after training, but also $7 \mathrm{~d}$ after. Mice

\footnotetext{
${ }^{3}$ Corresponding author.

E-mail mboccia@ffyb.uba.ar; fax 54-11-4964-8266.

Article and publication are at http://www.learnmem.org/cgi/doi/10.1101/ Im.150306.
}

that were over-reinforced in the learning trial exhibited a highretention performance $48 \mathrm{~h}$ after training. The immediate icv injection of HC-3 $(1 \mu \mathrm{g})$ after the first retention test significantly impaired retention performance over four consecutive days, whereas the saline-injected control group showed a slight, but significant performance decrease only at the last retention test. These results, taken together, suggest that HC-3 not only impaired consolidation, but also reconsolidation of an inhibitory avoidance task in mice, suggesting a critical participation of central cholinergic mechanisms in both memory processes.

Recently, Milekic and Alberini (2002) suggested that there is an increasing resistance to post-reactivation interfering disruption with a protein synthesis inhibitor (anisomycin) given subcutaneously, as the time interval from training increases in an inhibitory avoidance in rats. They suggested that old and wellconsolidated memories do not return to a labile state after reactivation; on the contrary, recently acquired memories become unstable when retrieved and subsequent recalls are impaired (Milekic and Alberini 2002).

In the present work, we investigate whether the degree of vulnerability of a reactivated memory to the deleterious effects of a central inhibitor of the synthesis of acetylcholine, a neurotransmitter that participates as a modulator in memory consolidation processes (Power et al. 2003), changes as a function of the time elapsing between original learning and retrieval.

\section{Results}

Training step-through latency differences among all of the groups used in these experiments were not significant $(\mathrm{TSTL}=10$ (8-2) sec; $\left.\mathrm{H}_{(13)}=4.20 ; P>0.05\right)$

When memory was evaluated either 2 or $7 \mathrm{~d}$ after training, HC-3 administered immediately after the first retention test significantly impaired retention latencies in five subsequent tests $(P<0.01$, in all cases as compared with the first retention test; 
Fig. 1A,B). These results confirm and extend previous ones (Boccia et al. 2004). On the contrary, both groups of saline-treated mice performed in all tests as well as on the first retention test, showing a slight decrease on the sixth test, but no statistical difference was found $(P>0.05)$ (Fig. $1 \mathrm{~A}, \mathrm{~B})$. When the first retention test was performed $14 \mathrm{~d}$ after training, although the deleterious effect of HC-3 on retention performance was still evident (Fig. 1C, $P<0.01$, in all cases as compared with the first retention test), the drop in the latencies was less than that observed after 2 or $7 \mathrm{~d}(P<0.05$, in all cases as compared with the corresponding retention test session) (Fig. 1A,B,C). Finally, when the first reexposure was delayed $30 \mathrm{~d}$ after training, HC-3 effects on retention latencies were no longer seen $(P>0.05$, in all cases as compared with the first retention test; Fig. 1D). Performance in saline-treated mice progressively decreased from the second to the sixth retention test, although, in any case, no significant differences were observed $(P>0.05)$. This observation led us to compare retention latencies of the corresponding trial of salinetreated mice across the four training-reactivation intervals, and no significant differences were found.

On the other hand, the deficit on retention performance was not observed in the group of mice non-re-exposed to the training context and injected with $\mathrm{HC}-348 \mathrm{~h}$ after training $(P>0.05$, compared with the saline-injected group) (Table 1$)$.

In the last experiment, the group of mice that received saline immediately after the first retention test (Fig. 2A) exhibited a normal retention performance both 2 and $21 \mathrm{~d}$ after training. Further, there were no significant differences in the retention scores between these times $(P>0.05)$. On the contrary, mice that received HC-3 immediately after memory retrieval exhibited, on the 21-d test, a severe impairment of retention performance $(P<0.01$, as compared with the saline-treated group) (Fig. 2A). Moreover, the group of mice that was tested 3 and $21 \mathrm{~d}$ after training exhibited a poor performance compared with the salinetreated control group $(P<0.01)$ (Fig. 2B). Finally, the retention performance $21 \mathrm{~d}$ after training was not significantly different in mice that were tested or not tested $3 \mathrm{~d}$ after training $(P>0.05)$ (Fig. 2A,B). These findings suggest that the effects of HC-3 administration immediately after the first memory retrieval on retention performance are long-lasting.

\section{Discussion}

One of the most important findings that should be taken into account when interpreting a reconsolidation hypothesis is the relationship between the age of the reactivated memory and the susceptibility to be disrupted. In this sense, it appears to occur that young reactivated memories were more susceptible to disruption by consolidation blockers, whereas older ones were not (Alberini 2005). This fact was clearly demonstrated for substances such as anisomycin or cycloheximide (Milekic and Alberini 2002; Alberini 2005), which are known as proteinsynthesis inhibitors (Davis and Squire 1984). However, less-extensive studies were aimed at assessing whether or not known consolidation modulatory circuits are also involved in post-retrieval memory processes (Przybyslawski et al. 1999; Sara 2000; Debiec and LeDoux 2004).

In the present study, we present evidence showing that recent memories (27-d old) are labile but remote ones (1430 -d old) become progressively insensitive to HC-3 administered immediately after reactivation.

Although protein synthesis inhibitors have been leading the research in this field, we must recognize that they have a highly nonspecific action. Hence, the studies with protein-synthesis inhibitors should take into account kinetics of the protein-synthesis inhibition and that not all of the systems that might be involved would be impaired when the hypothetical reconsolidation hypothesis is taking place, depending on the turnover of the proteins. This fact was not definitively solved up to now, and we think it is critical to elucidate that when using protein-synthesis inhibitors such as anisomycin as a pharmacological tool to interfere with either consolidation or reconsolidation memory processes.

Figure 1. Effect of icv infusion of SS $(1 \mu \mathrm{L})$ or $\mathrm{HC}-3(1 \mu \mathrm{g} / \mu \mathrm{L})$ given immediately after memory reactivation on retention performance at different training-memory reactivation test intervals. Each bar represents the medians and interquartile ranges ( $n=15$ mice/group, shocked mice) (A) $2 \mathrm{~d}$; (B) $7 \mathrm{~d}$; (C) $14 \mathrm{~d} ;(D) 30 \mathrm{~d}$. Test numbers represent successive test. Six retention tests were given, with an interval of $24 \mathrm{~h}$ between tests. ${ }^{* *} P<0.01$, in all cases compared with its respective test number 2 (MannWhitney U-test, two tailed), $\# P<0.05$, in all cases compared with its respective test number when memory was evaluated 2 or $7 \mathrm{~d}$ after training $(A, B)$ (Mann-Whitney U-test, two tailed). The behaviora experimental scheme is found above the graphs. 
Table 1. Effects of 48-h delayed icv injection of SS or HC-3 on retention performance in the absence of memory reactivation

\begin{tabular}{lc}
\hline \multicolumn{1}{c}{ Treatment } & Latencies to step-through (sec) ${ }^{\mathbf{a}}$ \\
\hline SS & $300(300-300)$ \\
HC-3 $(1 \mu \mathrm{g} /$ mice $)$ & $300(300-300)$ n.s. \\
\hline
\end{tabular}

n.s., not significant.

aTest was performed $72 \mathrm{~h}$ after training ( $n=15$ mice/group).

Data are expressed as the median and interquartile range.

n.s. $=P>0.05$, (Mann-Whitney U-test, two tailed).

On the contrary, using agonists and antagonists of specific receptors provides important clues to which processes might be occurring in the brain during memory storage. Although intracerebroventricular injections provide only mere hints of their site of action, it ensures that the drug effects are centrally mediated (McGaugh and Izquierdo 2000).

In addition to those studies using protein-synthesis inhibitors (Judge and Quartermain 1982; Nader et al. 2000; Anokhin et al. 2002; Sangha et al. 2003; for review, see Alberini 2005) other studies were performed in order to test the memory reconsolidation hypothesis using blockers of transcription factors and/or immediate early gene expression (Taubenfeld et al. 2001; Kida et al. 2002; Bozon et al. 2003; Lee et al. 2004; Merlo et al. 2005), inhibitors of kinases (Kelly et al. 2003; Koh and Bernstein 2003), or new potential learning situations (Gordon and Spear 1974; Walker et al. 2003; Boccia et al. 2005), and only a few studies found evidence of enhancement of memory with post-retrieval treatments (De Vietti et al. 1977; Horne et al. 1997, Rodriguez et al. 1999). This is an important issue if we want to compare consolidation vs. reconsolidation memory processes.

A system already known as a modulatory one, and involved in memory consolidation processes in different brain areas, behavioral tasks, and different species (Gold 2003; Power et al. 2003) was studied in this work. Hemicholinium (HC-3) is a specific inhibitor of the high-affinity choline uptake in brain cholinergic neurons. Accordingly, the pharmacological inhibition, at first, could only be attributed to the cholinergic synapse depressed function, although this dysfunction could modify additional neuronal systems (Decker and McGaugh 1991).

When HC-3 was administered icv immediately after training, memory consolidation was impaired when tested either 2 or $7 \mathrm{~d}$ after (Boccia et al. 2004). However, choline uptake inhibition immediately after retrieval seems to impair subsequent tests only when the retrieval session takes place close enough in time to the training procedures. These results are in accordance, at first instance, with those reported by Milekic and Alberini (2002) using a protein-synthesis inhibitor.

Further, a separated group of mice that was injected with HC-3 $48 \mathrm{~h}$ after training, but did not experience the reactivation session, performed as well as a saline-injected control group at day 3 post-acquisition of the original response. These facts, which are similar to those previously reported by Nader et al. (2000) and Milekic and Alberini (2002), suggest that the impairment of retention induced by post-retrieval administration of HC-3 could not be attributed to nonspecific influences on performance.

Similar results, indicating a temporally graded requirement for protein synthesis after recall, have been reported by others who have used different models, systems, and species (Litvin and Anokhin 2000; Eisenberg and Dudai, 2004; Suzuki et al. 2004). Suzuki et al. (2004) found that increasing the strength of the memory (by increasing the number of shocks during training), increased the resistance of the fear memory to be disrupted by protein-synthesis inhibitors; moreover, longer re-exposures were required to induce performance impairment after postreactivation of stronger memories. We are currently studying whether the cholinergic system participates in post-retrieval memory consolidation processes modifying the retrieval test conditions (e.g., longer re-exposures).

Lack of reversal of amnesia could support storage-deficit interpretation. Several groups have observed recovery of memory following post-retrieval retention performance impairment within hours, days, or weeks (Mactutus et al. 1979; Vianna et al. 2001; Anokhin et al. 2002; Bahar et al. 2004; Lattal and Abel 2004; Power et al. 2006), suggesting that the retention performance impairment induced by post-retrieval treatment may be temporary. This is consistent with the interpretation that such treatments may temporally disrupt memory retrieval (Riccio et al. 2002; Arshavsky 2003; Lattal and Abel 2004). However, Duvarci and Nader (2004) reported lack of spontaneous recovery of an auditory fear conditioning after intralateral amygdala infu-
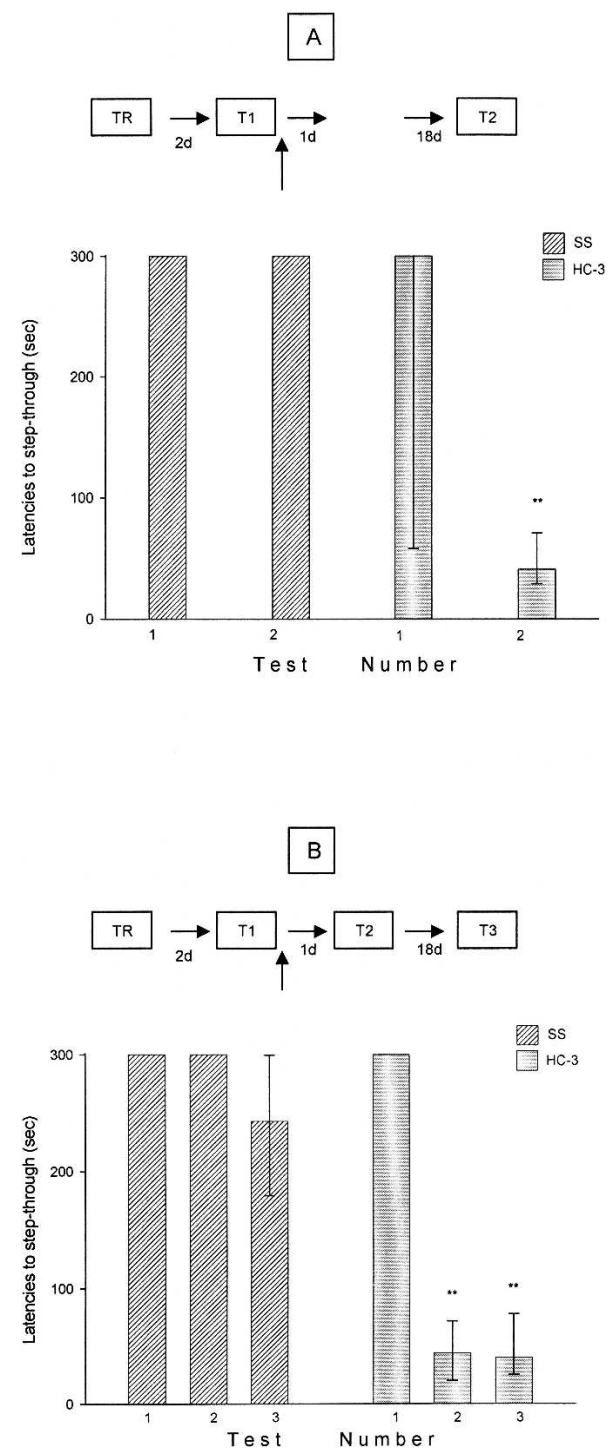

Figure 2. Long lasting effects of icv infusion of HC-3 $(1 \mu \mathrm{g} / \mu \mathrm{L})$ on retention performance after memory reactivation. Each bar represents the medians and interquartile ranges. (TR, training) ( $n=15$ mice/group). (A) Mice were tested only $21 \mathrm{~d}$ after training. (B) Mice were tested twice $\left(48 \mathrm{~h}\right.$ and $21 \mathrm{~d}$ ) after training. ${ }^{* *} P<0.01$, in all cases with respect to first retention trial (Mann-Whitney U-test, two tailed). The behavioral experimental scheme is found above the graphs. 
sions of anisomycin following memory reactivation, and we recently reported that no spontaneous recovery was observed after the exposure to a new potential learning situation after memory reactivation of an inhibitory avoidance task in mice (Boccia et al. 2005). As we did not find recovery of retention performance at least $21 \mathrm{~d}$ after memory reactivation of a 2-d-old memory in mice treated with $\mathrm{HC}-3$, our results are in accordance with the storagedeficit interpretation. However, we cannot definitively discard a possible retrieval deficit yet, since a poor performance does not evidence absence of memory (Cahill et al. 2001). The potential reasons for these discrepancies are not clear, but they probably reflect differences between the learning tasks used. We must mention that in Figure 1C, it seems that with repeated reexposures to the context, an improved performance is observed, suggesting spontaneous recovery of the original memory (no statistical difference was found). Experiments are in progress in order to determine spontaneous recovery at different time points from training, either with or without repeated re-exposures.

However, is it possible that, when given after memory retrieval, HC-3 facilitates the extinction of the avoidance response? Although we do not have a definitive answer, some comments appear to be necessary. As stated before, the mice were overreinforced during the learning trial in order to reduce the influence of extinction. Additionally, we considered evidence that suggests a protective effect of over-reinforcement against the amnesic properties of some pharmacological treatments affecting central cholinergic mechanisms (Durán-Arévalo et al. 1990). This might be the case when HC-3 was given after a retention test. Performance impairment was evident from the second to the sixth retention test in HC-3 treated mice when administered immediately after retrieval. If HC-3 was facilitating extinction, which is a new learning (Myers and Davis 2002), then the drug might be retroactively enhancing memory consolidation of a nonreinforced conditioning stimulus presentation (i.e., extinction). This seems unlikely, because when HC-3 was given immediately after training impaired memory consolidation of the original learning response (Boccia et al. 2004), it has been consistently found that cholinergic blockade results in retrograde amnesia in various animal species and different learning tasks (Ridley et al. 1984; Prado-Alcalá et al. 1993).

It is useful to consider the competition model proposed by Nader et al. (2000) and Nader (2003). Accordingly, when the retrieval session induces significant extinction, then it is the extinction memory that is labile and sensitive to disruption. Conversely, when a protocol is used that does not lead to significant extinction during retrieval, then the reconsolidation is blocked. Since our mice were over-reinforced during the learning trial, it seems a reasonable possibility that in this study there was no extinction. Furthermore, if HC-3 was facilitating the extinction of the inhibitory avoidance response, we should expect a spontaneous recovery (Bouton 1993) of the original learning, and that was not the case, at least not when mice were tested $21 \mathrm{~d}$ after training.

However, there are some confounding results about the participation of the central cholinergic system on memory extinction processes (for review, see Mason 1983). The muscarinic antagonist scopolamine reversed extinction of a shock-avoidance conditioning after systemic injection in the rat was submitted to an extensive extinction training (Prado-Alcalá et al. 1994), and memory extinction of a conditioned taste-aversion response was not affected when scopolamine was infused in the insular cortex of the rat (Berman and Dudai 2001; Berman et al. 2003). On the contrary, oxotremorine, a muscarinic agonist, enhanced extinction of a contextual fear memory in rats when infused in the right basolateral amygdala (M.M. Boccia, C.M. Baratti, and J.L. McGaugh, unpubl.).
One point that deserves attention and further studies is the difference observed in the retention latencies at different training-test intervals; the longer the interval, the faster the reduction in retention latencies. It could be attributable to an earlier development of an extinction phenomenon (Myers and Davis 2002). Moreover, $30 \mathrm{~d}$ after training, HC-3 no longer affects retention performance in subsequent tests when given immediately after reactivation, and the extinction of saline and HC-3-treated mice seem very similar. Studies are in progress in order to elucidate this interesting observation.

Mechanisms of memory perseverations are barely known (Dudai and Eisenberg 2004; Alberini 2005). How does memory stabilize over time? It is likely that the labile nature of a reactivated memory reveals that reactivation of the memory trace is an integral aspect of a single, extended consolidation process, at least in our experimental conditions using HC-3.

We think it is imperative to perform these kinds of studies in order to elucidate whether the reconsolidation memory process is linked to, and perhaps part of, the better known and characterized period that follows a learning experience described $100 \mathrm{yr}$ ago by Müller and Pilzecker (1900) in their "consolidation theory of memory."

\section{Materials and Methods}

\section{Subjects}

CF-1 male mice (FUNDACAL, Argentina) were used (age: 60-70 d; weight: $25-30 \mathrm{~g}$ ). They were caged in groups of 15 and remained housed throughout the experimental procedures. The mice were kept in a climatized animal room $\left(21-23^{\circ} \mathrm{C}\right)$ maintained on a 12-h light/12-h dark cycle (lights on at 06:00 h), with ad libitum access to dry food and tap water. Experiments were carried out in accordance with the National Institutes of Health Guide for the Care and Use of Laboratory Animals (NIH Publication No. 80-23/ 96), and local regulations. All efforts were made to minimize animal suffering and to reduce the number of animals used.

\section{Inhibitory avoidance task}

Inhibitory avoidance behavior was studied in a one-trial learning, step-through type situation (Boccia et al. 2004), which utilizes the natural preference of mice for a dark environment. The apparatus consists of a dark compartment $(20 \times 20 \times 15 \mathrm{~cm})$ with a stainless-steel grid floor and a small $(5 \times 5 \mathrm{~cm})$, illuminated elevated platform attached to its front center. The mice were not habituated to the dark compartment before the learning trial. During training each mouse was placed on the platform and received a footshock as it stepped into the dark compartment (1.2 $\mathrm{mA}, 50 \mathrm{~Hz}, 1 \mathrm{sec}$ ) (Boccia et al. 2004). The footshock-training conditions yielded median retention scores at the ceiling and were used in order to reduce the influence of extinction on retention performance (see below).

At the times indicated for each experimental group, the retention tests were performed. Each mouse was placed on the platform again and the step-through latency was recorded. The retention test was finished either when the mouse stepped into the dark compartment or failed to cross within 300 sec (ceiling score). In the latter case, the mouse was immediately removed from the platform and assigned a score of 300 sec (ceiling score). In the retention test session, the footshock was omitted.

Eight different groups of 15 mice each were trained in the inhibitory avoidance task; $2,7,14$, or $30 \mathrm{~d}$ after training, the mice were submitted to the first retention test trial. Immediately after, mice received an icv injection of saline $(1 \mu \mathrm{L})$ or HC-3 $(1 \mu \mathrm{g})$. One day later and for four consecutive days at $24 \mathrm{~h}$ intervals, both groups of mice were tested. Another two groups of 15 mice each were trained, and $48 \mathrm{~h}$ after training they were injected with saline $(1 \mu \mathrm{L})$ or HC-3 $(1 \mu \mathrm{g})$ and were tested for retention $72 \mathrm{~h}$ after training.

Finally, four groups of 15 mice each were trained in the inhibitory avoidance task; $48 \mathrm{~h}$ later they were tested and re- 
ceived an immediate icv infusion of saline $(1 \mu \mathrm{L})$ or HC-3 $(1 \mu \mathrm{g})$. The half of the mice receiving either saline or HC-3 were tested again $21 \mathrm{~d}$ after training. The remaining two groups (saline or HC-3) were submitted to a second retention test $72 \mathrm{~h}$ after training and were retested $21 \mathrm{~d}$ after training.

\section{Drug administration}

The mice were prepared $48 \mathrm{~h}$ before testing for the subsequent icv injection of saline or drug solution so that a minimum of time would be needed for the injection, which was administered under light ether anesthesia in a stereotaxic instrument (Boccia et al. 2004). Saline or HC-3 solution was injected unilaterally at random into either the left or right lateral ventricle at a volume of $1.0 \mu \mathrm{L}$. The injection coordinates were $-0.34 \mathrm{~mm}$ with respect to bregma, $1.00 \mathrm{~mm}$ to the right or left from the central, and 2.10 $\mathrm{mm}$ in depth (Franklin and Paxinos 1997). Within 2 min after the first retention test, the injections were performed over $90 \mathrm{sec}$ (Boccia et al. 2004).

\section{Statistical analysis}

Data are expressed as median latencies to step-through during the retention test and interquartile ranges, and were analyzed, when appropriate, with the nonparametric analysis of variance of Kruskal-Wallis, and the differences between groups were estimated by individual Mann-Whitney U-tests (two tailed) (Siegel 1956). In all cases, $P$-values $<0.05$ were considered significant.

\section{Acknowledgments}

This work was supported by grant B028 from the University of Buenos Aires. M.G.B. is a fellow from UBA. M.M.B., G.B.A., and C.M.B. are members of CONICET. We thank James L. McGaugh for his valuable comments on the original draft.

\section{References}

Alberini, C.M. 2005. Mechanisms of memory stabilization: Are consolidation and reconsolidation similar or distinct processes? Trends Neurosci. 28: 51-56.

Anokhin, K.V., Tiunova, A.A., and Rose, S.P.R. 2002. Reminder effects-reconsolidation or retrieval deficit? Pharmacological dissection with protein synthesis inhibitors following reminder for passive-avoidance task in young chicks. Eur. J. Neurosci. 15: $1759-1765$.

Arshavsky, Y.L. 2003. Long-term memory: Does it have a structural or chemical basis? Trends Neurosci. 26: 465-466.

Bahar, A., Dorfman, N., and Dudai, Y. 2004. Amygdalar circuits required for either consolidation or extinction of taste aversion memory are not required for reconsolidation. Eur. J. Neurosci. 19: 1115-1118.

Berman, D.E. and Dudai, Y. 2001. Memory extinction, learning anew, and learning the new: Dissociations in the molecular machinery of learning in cortex. Science 291: 2417-2419.

Berman, D.E., Shoshi, H., Stehberg, J., Bahar, A., and Dudai, Y. 2003. Conflicting processes in the extinction of conditioned taste aversion: Behavioral and molecular aspects of latency, apparent stagnation and spontaneous recovery. Learn. Mem. 10: 16-25.

Boccia, M.M., Blake, M.G., Acosta, G.B., and Baratti, C.M. 2004. Memory consolidation and reconsolidation of an inhibitory avoidance response in mice. Effects of i.c.v. injections of hemicholinium-3. Neuroscience 124: 735-741.

- 2005. Memory consolidation and reconsolidation of an inhibitory avoidance task in mice. Effects of a new different learning task. Neuroscience 135: 19-29.

Bouton, M.E. 1993. Context, time and memory retrieval in the interference paradigms of pavlovian conditioning. Psychol. Bull. 114: 80-99.

Bozon, B., Davis, S., and Laroche, S. 2003. A requirement for the early gene zif268 in reconsolidation of recognition memory after retrieval. Neuron 40: 695-701.

Cahill, L., McGaugh, J.L., and Weinberger, N.M. 2001. The neurobiology of learning and memory: Some reminders to remember. Trends Neurosci. 24: 578-581.

Davis, H.P. and Squire, L.R. 1984. Protein synthesis and memory: A review. Psychol. Bull. 96: 518-559.

Debiec, J. and LeDoux, J.E. 2004. Disruption of reconsolidation but not consolidation of auditory fear conditioning by noradrenergic blockade in the behaviour. Neuroscience 129: 267-272.

Decker, M.W. and McGaugh, J.L. 1991. The role of interactions between the cholinergic system and other neuromodulatory systems in learning and memory. Synapse 7: 151-168.

DeVietti, T.L., Conger, G.L., and Kirkpatrick, B.R. 1977. Comparison of the enhancement gradients of retention obtained with stimulation of the mesencephalic reticular formation after training or memory reactivation. Physiol. Behav. 19: 549-554.

Dudai, Y. and Eisenberg, M. 2004. Rites of passage of the engram: Reconsolidation and the lingering consolidation hypothesis. Neuron 44: 93-100.

Durán-Arévalo, M. Cruz-Morales, S.E., and Prado-Alcalá, R.A. 1990. Is acetylcholine involved in memory consolidation of over-reinforced learning? Brain Res. Bull. 24: 725-727.

Duvarci, S. and Nader, K. 2004. Characterization of fear memory reconsolidation. I. Neurosci. 24: 9269-9275.

Eisenberg, M. and Dudai, Y. 2004. Reconsolidation of fresh, remote, and extinguished fear memory in medaka: Old fears don't die. Eur. J. Neurosci. 20: 3397-3403.

Franklin, K.B.J. and Paxinos, G. 1997. The mouse brain in stereotaxic coordinates. Academic Press, London, UK.

Gold, P.E. 2003. Acetylcholine modulation of neural systems involved in learning and memory. Neurobiol. Learn. Mem. 80: 194-210.

Gordon, W.C. and Spear, N.E. 1974. Effect of reactivation of a previously acquired memory on the interaction between memories in the rat. J. Exp. Psychol. 99: 349-355.

Horne, C.A., Rodriguez, W.A., Wright, T.P., and Padilla, J.L. 1997. Time-dependent effects of fructose on the modulation of a reactivated memory. Prog. Neuropsychopharmacol. Biol. Psychiatry 21: $649-658$.

Judge, M.E. and Quartermain, D. 1982. Characteristics of retrograde amnesia following reactivation of memory in mice. Physiol. Behav. 28: $585-590$.

Kelly, A., Laroche, S., and Davis, S.W. 2003. Activation of mitogen-activated protein kinase/extracellular signal-regulated kinase in hippocampal circuitry is required for consolidation and reconsolidation of recognition memory. J. Neurosci. 12: 5354-5360.

Kida, S., Josselyn, S.A., Ortiz, S.P.D., Kogan, J.H., Chevere, I., Masushige, S., and Silva, A.J. 2002. CREB required for the stability of new and reactivated memories. Nat. Neurosci. 5: 348-355.

Koh, M.T. and Bernstein, I.L. 2003. Inhibition of protein kinase A activity during conditioned taste aversion retrieval: Interference with extinction or reconsolidation of memory? Neuroreport 14: 405-407.

Lattal, K.M. and Abel, T. 2004. Behavioral impairments caused by injections of the protein synthesis inhibitor anisomysin after contextual retrieval reverse with time. Proc. Natl. Acad. Sci. 101: $4667-4672$.

Lee, J.L.C., Everitt, B.J., and Thomas, K.L. 2004. Independent cellular processes for hippocampal memory consolidation and reconsolidation. Science 304: 839-843.

Litvin, O.O. and Anokhin, K.V. 2000. Mechanisms of memory reorganization during retrieval of acquired behavioral experience in chicks: The effects of protein synthesis inhibition in the brain. Neurosci. Behav. Physiol. 30: 671-678.

Mactutus, C.F., Riccio, D.C., and Ferek, J.M. 1979. Retrograde amnesia for old (reactivated) memory: Some anomalous characteristics. Science 204: 1319-1320.

Mason, S.T. 1983. The neurochemistry and pharmacology of extinction behavior. Neurosci. Biobehav. Rev. 7: 325-347.

McGaugh, J.L. 1966. Time-dependent processes in memory storage. Science 153: 1351-1358.

. 2000. Memory-A century of consolidation. Science 287: 248-251.

McGaugh, J.L. and Izquierdo, I. 2000. The contribution of pharmacology to research on the mechanisms of memory formation. Trends Pharmacol. Sci. 21: 208-210.

Merlo, E., Freudenthal, R., Maldonado, H., and Romano, A. 2005. Activation of the transcription factor NF- $\kappa$ B by retrieval is required for long-term memory reconsolidation. Learn. Mem. 12: 23-29.

Milekic, M.H. and Alberini, C.M. 2002. Temporally graded requirement for protein synthesis following memory reactivation. Neuron 36: $521-525$.

Misanin, J.R., Miller, R.R., and Lewis, D.J. 1968. Retrograde amnesia produced by electroconvulsive shock after reactivation of a consolidated memory trace. Science 160: 203-204.

Müller, G.E. and Pilzecker, A. 1900. Experimentelle Beiträge zur Lehre vom Gedächtnis. Z. Psychol. Ergänzungsband 1: 1-300.

Myers, K.M. and Davis, M. 2002. Behavioral and neural analysis of extinction. Neuron 36: 567-584.

Nader, K. 2003. Memory traces unbound. Trends Neurosci. 26: 65-72.

Nader, K., Schafe, G.E., and LeDoux, J.E. 2000. Fear memories require protein synthesis in the behaviour for reconsolidation after retrieval. Nature 406: 722-726.

Power, A.E., Vazdarjanova, A., and McGaugh, J.L. 2003. Muscarinic 
cholinergic influences in memory consolidation. Neurobiol. Learn. Mem. 80: 178-193.

Power, A.E., Berlau, D.J., McGaugh, J.L., and Steward, O. 2006. Anisomycin infused into the hippocampus after a retrieval test temporarily impairs inhibitory avoidance performance with a brief re-exposure and impairs extinction with an extended re-exposure. Learn. Mem. 13: 27-34.

Prado-Alcalá, R.A., Fernández-Ruiz, J., and Quirate, G.L. 1993. Cholinergic neurons and memory. In Synaptic transmission 2 (ed. T.W. Stone), pp. 57-69. Taylor and Francis Ltd, London, UK.

Prado-Alcalá, R.A., Haiek, M., Rivas, S., Roldán-Roldán, G., and Quirarte, G.L. 1994. Reversal of extinction by scopolamine. Physiol. Behav. 56: $27-30$.

Przybyslawski, J., Roullet, P., and Sara, S.J. 1999. Attentuation of emotional and nonemotional memories after their reactivation: Role of $\beta$ adrenergic receptors. J. Neurosci. 19: 6623-6628.

Riccio, D.C., Moody, E.W., and Millin, P.M. 2002. Reconsolidation reconsidered. Integr. Physiol. Behav. Sci. 37: 245-253.

Ridley, R.M., Baratt, N.G., and Baker, H.F. 1984. Cholinergic learning deficit produced by scopolamine and hemicholinium. Psychopharmacology 83: 340-344.

Rodriguez, W.A., Horne, C.A., and Padilla, J.L. 1999. Effects of glucose and fructose on recently reactivated and recently acquired memories. Prog. Neuropsychopharmacol. Biol. Psychiatry 23: $1285-1317$.

Sangha, S., Scheibenstock, A., and Lukowiak, K. 2003. Reconsolidation of a long-term memory in Lymnaea requires new protein and RNA synthesis and the soma of right pedal dorsal 1. J. Neurosci. 23: 8034-8040.

Sara, S.J. 2000. Retrieval and consolidation: Toward a neurobiology of remembering. Learn. Mem. 4: 356-364.

Siegel, S. 1956. Non-parametric statistics for the behavioural sciences. McGraw-Hill, New York.

Squire, L.R. and Alvarez, P. 1995. Retrograde amnesia and memory consolidation: A neurobiology perspective. Curr. Opin. Neurobiol. 5: $169-177$.

Suzuki, A., Josselyn, S.A., Frankland, P.W., Masushige, S., Silva, A.J., and Kida, S. 2004. Memory reconsolidation and extinction have distinct temporal and biochemical signatures. J. Neursoci. 24: 4787-4795.

Taubenfeld, S.M., Milekic, M.H., Monti, B., and Alberini, C.M. 2001. The consolidation of new but not reactivated memory requires hippocampal C/EBPß. Nat. Neurosci. 4: 813-818.

Vianna, M.R.M., Szapiro, G., McGaugh, J.L., Medina, J.H., and Izquierdo, I. 2001. Retrieval of memory for fear-motivated training initiates extinction requiring protein synthesis in the rat hippocampus. Proc. Natl. Acad. Sci. 98: 12251-12254.

Walker, M.P., Brakefield, T., Hobson, J.A., and Stickgold, R. 2003. Dissociable stages of human memory consolidation and reconsolidation. Nature 425: 616-620.

Received November 28, 2005; accepted in revised form March 7, 2006. 


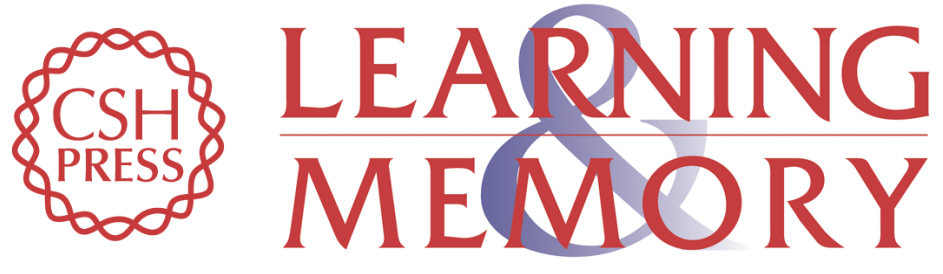

\section{Post-retrieval effects of icv infusions of hemicholinium in mice are dependent on the age of the original memory}

Mariano M. Boccia, Mariano G. Blake, Gabriela B. Acosta, et al.

Learn. Mem. 2006, 13:

Access the most recent version at doi:10.1101//m.150306

References This article cites 55 articles, 15 of which can be accessed free at:

http://learnmem.cshlp.org/content/13/3/376.full.html\#ref-list-1

License

Email Alerting Receive free email alerts when new articles cite this article - sign up in the box at the Service top right corner of the article or click here. 